\title{
Growth rate enhancement of silicon-carbide oxidation in thin oxide regime
}

\author{
Yasuto Hijikata and Hiroyuki Yaguchi \\ Saitama University \\ Japan \\ Sadafumi Yoshida \\ National Institute of Advanced Industrial Science and Technology \\ Japan
}

\section{Introduction}

Among wide band-gap semiconductor materials, only silicon carbide ( $\mathrm{SiC}$ ) can have $\mathrm{SiO}_{2}$ layers, known as superior insulating films for metal-oxide-semiconductor (MOS) applications, on its surface by thermally oxidizing it, similarly to $\mathrm{Si}$ (2). In addition, its physical properties, such as high-breakdown electric field and high thermal conductivity, compared with $\mathrm{Si}$, are suitable for high-speed switching and low-power-loss electronic devices. For these reasons, $\mathrm{SiC}$ metal-oxide-semiconductor field-effect transistors (MOSFETs) are expected to have superior specifications that cannot be obtained using Si. However, the electrical characteristics of $\mathrm{SiC}$ MOSFETs, such as on-resistance, are seriously poorer than those predicted from SiC bulk properties (1). It has been considered that these poor characteristics result from a high interface state density (3). Therefore, the clarification of the structure of SiC-oxide interfaces or the formation mechanism of the interface layer is one of the most important subjects to be studied to improve the electrical characteristics of $\mathrm{SiC}$ MOS devices.

In a previous work, we have performed real-time observation of $\mathrm{SiC}$ thermal oxidation using an in-situ ellipsometer (4). The results show that the oxidation-time dependence of oxide thickness can be represented using the Deal-Grove (D-G) model (5), which has been originally proposed for the explanation of Si oxidation. Song et al. (6) have modified the D-G model for application to $\mathrm{SiC}$ oxidation taking the presence of carbon into account. They have concluded that a linear-parabolic formula can also be applicable to $\mathrm{SiC}$ oxidation, although the parabolic term includes the contribution from the diffusion of $\mathrm{CO}$ or $\mathrm{CO}_{2}$ molecules from the $\mathrm{SiC}-$ oxide interface to the surface as well as that of oxygen from the surface to the interface. On the other hand, it is well known that the oxidation behavior of Si cannot be explained using the D-G model, i.e., a simple linear-parabolic model, particularly at the initial oxidation stage. Accordingly, several models have been proposed for the explanation of Si oxidation (7-12). In this work, we have studied $4 H$-SiC oxidation at the initial stage in more detail by performing in-situ spectroscopic ellipsometry and discussed the oxidation mechanism of SiC by comparing it with that of Si. 


\section{Experimental procedure}

$4 H$-SiC (0001) C-face and (0001) Si-face epitaxial layers with $8^{\circ}$ off-angles ( $n$-type, $N_{d}-N_{a}=$ around $6 \times 10^{15} \mathrm{~cm}^{-3}$ ) were used in this study. After Radio Corporation of America (RCA) cleaning was executed, an epiwafer was placed into the in-situ spectroscopic ellipsometer and was heated at temperatures between 890 and $1220^{\circ} \mathrm{C}$. The oxidation was performed also at oxygen partial pressures between 0.02 and 1.0 atm at $1150^{\circ} \mathrm{C}$ for $\mathrm{C}$-face and between 0.1 and $1.0 \mathrm{~atm}$ at $1200^{\circ} \mathrm{C}$ for Si-face. Prior to the oxidation, ellipsometric parameters $(\Psi, \Delta)$ were measured in the argon atmosphere to determine the optical constants of $\mathrm{SiC}$ at the oxidation temperatures. Then, oxygen gas was introduced into the chamber and the oxidation time dependence of $(\Psi, \Delta)$ was monitored during dry oxidation. Spectroscopic ellipsometric measurements were carried out at wavelengths between 310 and $410 \mathrm{~nm}$, and at an angle of incidence of $75.8^{\circ}$.

In the evaluation of oxide thickness from the ellipsometric measurements, we assumed threelayer structures, i.e., the sample is composed of a $\mathrm{SiO}_{2}$ layer, an interface layer, and a $\mathrm{SiC}$ substrate. We have evaluated the thickness of $\mathrm{SiO}_{2}$ layers under the assumption that the interface layer is $1 \mathrm{~nm}$ in thickness and has the optical constants obtained in the previous study (13). The details of the spectroscopic ellipsometric measurements and the evaluation of oxide thickness were described elsewhere $(4 ; 14)$.

\section{Results and Discussion}

\subsection{Oxidation rate at various oxidation temperatures}

We have applied the D-G model to the relations between oxide thickness, $X$, and oxidation time, $t$, observed, and have obtained the values of the parameters $B / A$ and $B$ in the $D-G$ equation (5) by fitting the calculated curve to the observed values in the entire thickness range. The fits are in general good at all of the oxidation temperatures, as reported previously (4). However, we found that, in the thickness range less than approximately $20 \mathrm{~nm}$, there is a tendency for the observed values to be slightly larger than the calculated ones. To investigate these discrepancies in more detail, we have derived the oxidation rates $d X / d t$ as a function of oxide thickness. Figure 1 shows the values of $d X / d t$ of $\operatorname{SiC}(000 \overline{1}) \mathrm{C}$-face as a function of oxide thickness at various oxidation temperatures. As shown in this figure, we have successfully obtained the values of the oxide growth rate even in the thin oxide thickness range of less than $10 \mathrm{~nm}$ by real-time in-situ observation. We have failed to fit the $d X / d t$ against the $X$ curves calculated using the D-G equation to the observed ones over the entire oxide thickness range measured at any oxidation temperature. However, as shown by the solid lines in Fig. 1, we can well fit the calculated curves to the observed ones when the thickness range of curve fitting is limited in the range thicker than approximately $20 \mathrm{~nm}$. In this case, the figure clearly shows that the values of $d X / d t$ in the thin thickness region are larger than the values given using the D-G equation at all the oxidation temperatures measured. These results suggest the existence of an oxidation process having a larger growth rate than that predicted by the D-G model. 


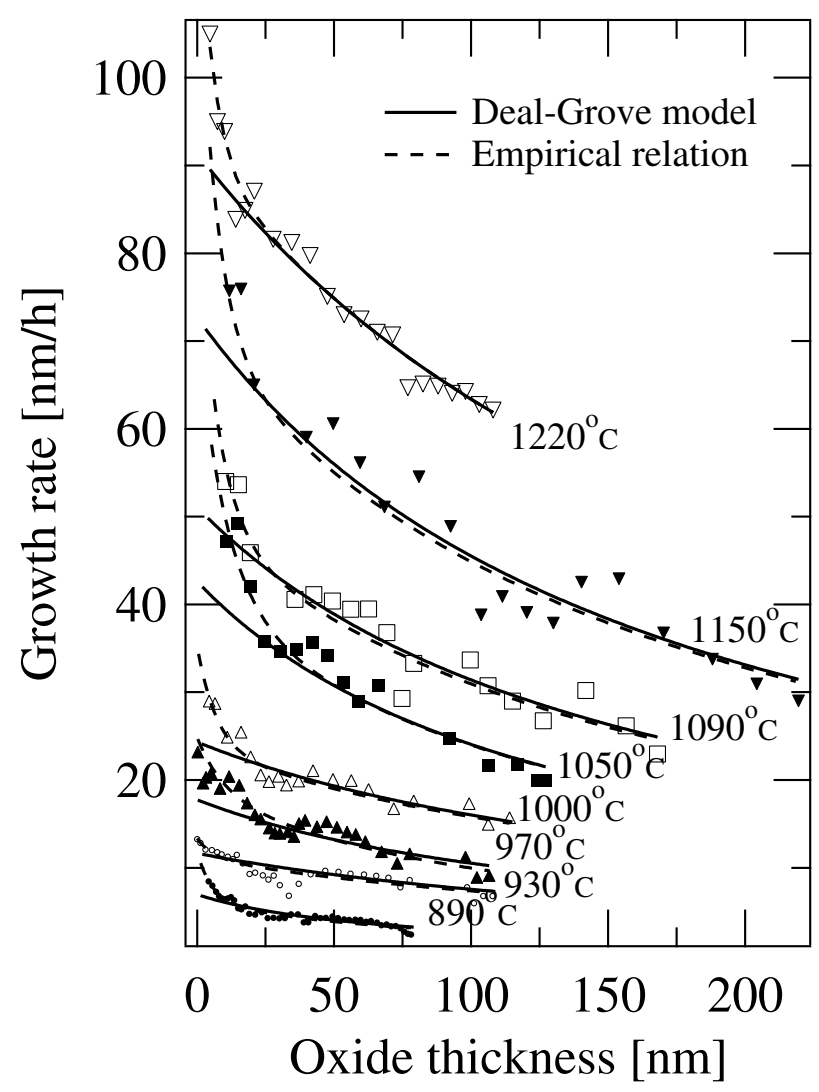

Fig. 1. Oxide thickness dependences of oxidation rate for $\mathrm{SiC}(000 \overline{1}) \mathrm{C}$-face at various oxidation temperatures. The solid and dashed lines denote the values derived from the Deal-Grove model eq. (1) (5) and those from the empirical relation eq. (2) $(8 ; 9)$, respectively.

Figure 2 shows the growth rate $d X / d t$ of $\operatorname{SiC}(0001)$ Si-face as a function of the oxide thickness $X$ at various oxidation temperatures (15). The figure shows that the values obtained are almost constant in the larger thickness range in this study at any oxidation temperature. The reason for this constant thickness dependence will be discussed later. While in the smaller thickness range, the values of $d X / d t$ are not constant but increase with decreasing oxide thickness, i.e., the oxide growth rate enhancement occurs at any temperature in this study, as in the case of C-face. 


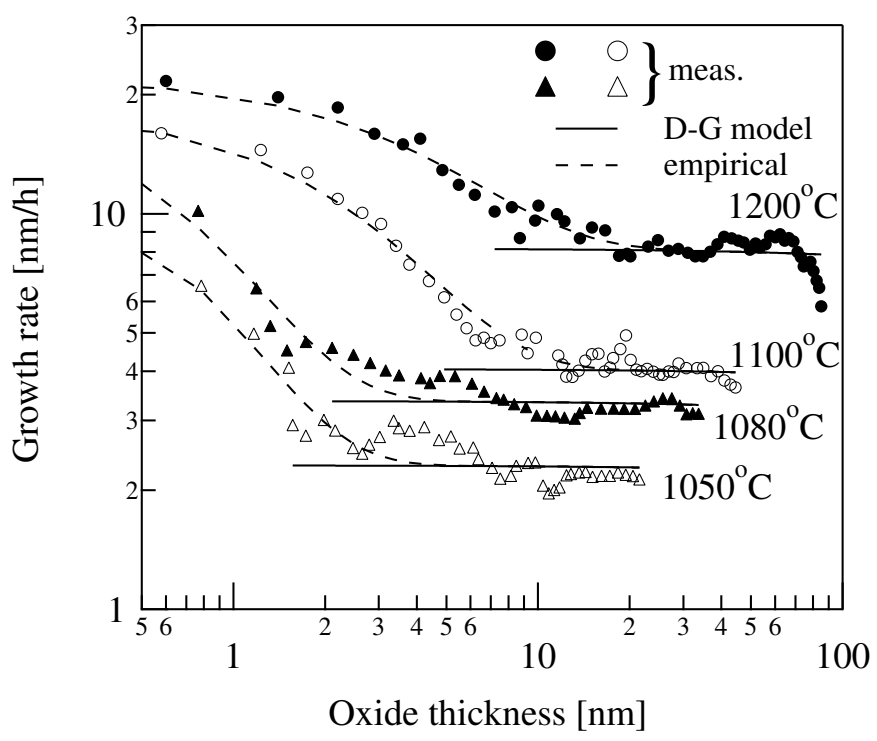

Fig. 2. Oxide thickness dependence of s growth rate for $\mathrm{SiC}$ (0001) Si-face at various oxidation temperatures (15). The solid and dashed lines denote the same values as those in Fig. 1.

\subsection{Oxidation rate at various oxygen partial pressures}

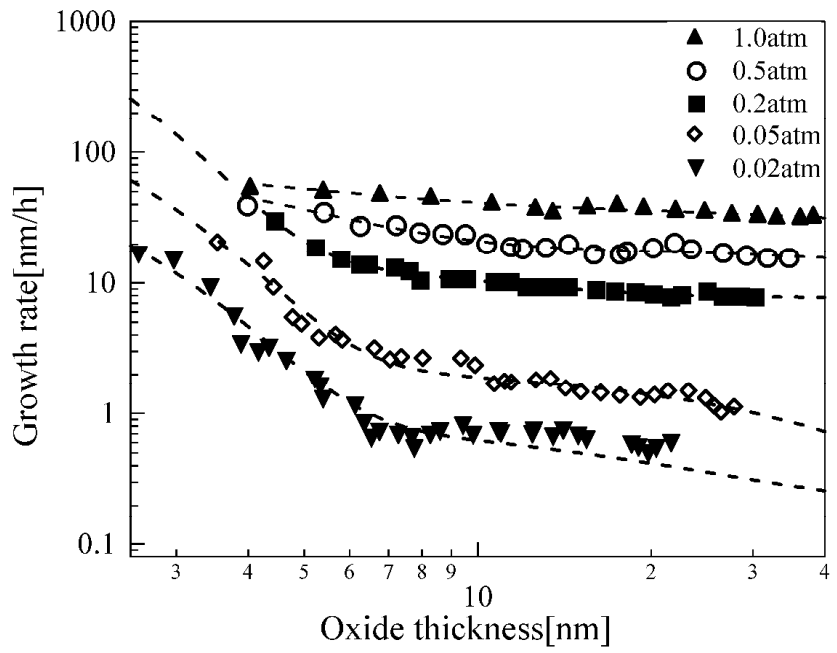

Fig. 3. Oxide growth rate of C-face as a function of oxide thickness at various oxygen partial pressures (17). The dashed curves denote the ones fitted to the experimental data using eq. (2). 
Figure 3 shows the oxide growth rate $d X / d t$ as a function of the oxide thickness for C-face at various oxygen partial pressures. Since the initial oxide growth rates at pressures higher than 0.2 atm was too fast, we could not accurately derive them, and thus the experimental data are not shown in this figure. As can be seen from this figure, the oxide growth rate slowly increases with decreasing oxide thickness in the thick oxide regime, and then, steeply increases with decreasing thickness. Figure 4 shows the oxide thickness dependence of $d X / d t$ at various oxygen partial pressures for $\mathrm{Si}$-face. This figure also shows that the oxide growth rate enhancement occurs at any partial pressure, as in the case of C-face.

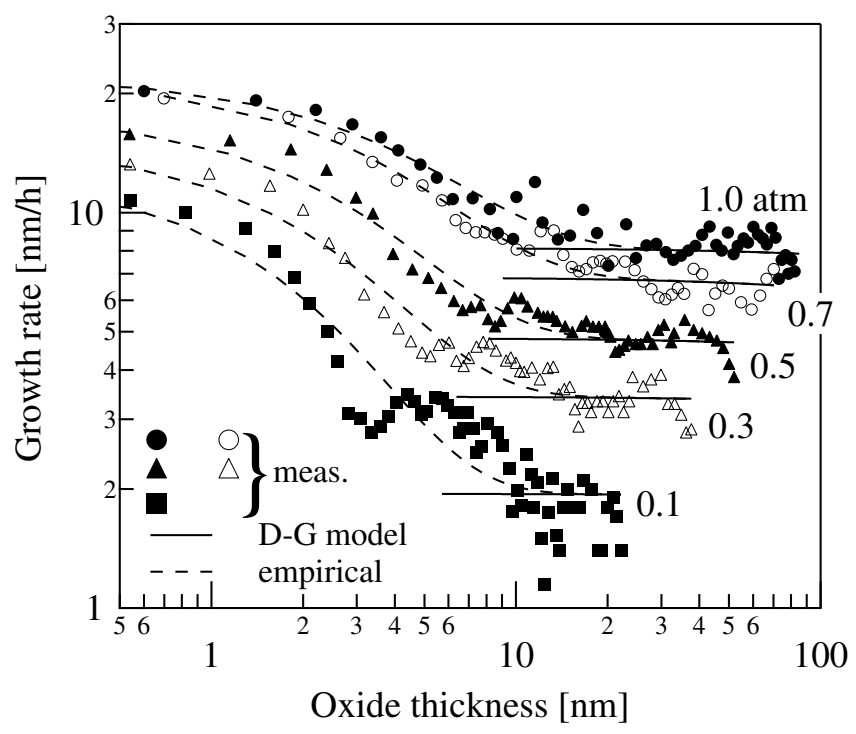

Fig. 4. Oxide thickness dependence of growth rate for Si-face at various oxygen partial pressures (15). The solid and dashed lines denote the same values as those in Fig. 1.

\subsection{Massoud Empirical Relation}

The kinetic model of Si oxidation that is most often taken as references is the Deal-Grove model proposed by Deal and Grove (5). According to this model, the beginning of oxidation is limited to interfacial oxidation reaction and, after oxidation proceeds, the rate-imiting process is transferred from the interfacial reaction to diffusion of oxidants in $\mathrm{SiO}_{2}$. This process is expressed by the following equation given by Deal and Grove as (5)

$$
\frac{d X}{d t}=\frac{B}{A+2 X}
$$

where $B / A$ and $B$ are denoted as the linear and parabolic rate constants of oxidation, respectively. It is noted that $B / A$ and $B$ are the rate coefficients for the interfacial reaction and the diffusion of oxidants rate-limiting step, respectively. However, it is well known that the oxidation rate of $\mathrm{Si}$ in the thin oxide thickness range cannot be reproduced by this equation and, hence, several models to describe the growth rate enhancement in thin oxide regime have 


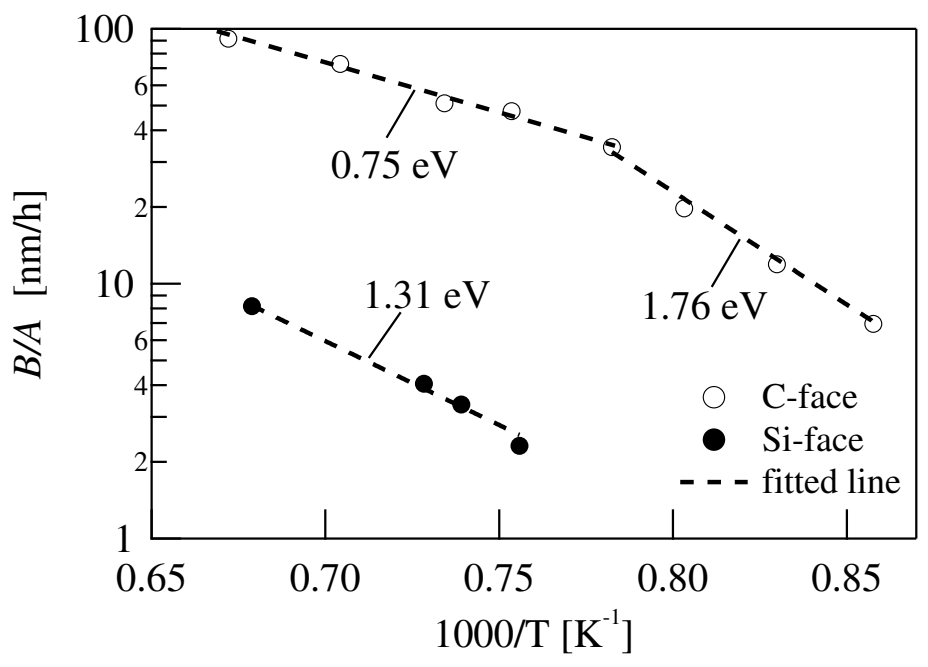

Fig. 5. Arrhenius plots of the linear rate constant $B / A$ for $C$ - and Si-faces.

been proposed (7-12). Among them, Massoud et al. $(8 ; 9)$ have proposed an empirical relation for the oxide thickness dependence of oxidation rate, that is, the addition of an exponential term to the D-G equation,

$$
\frac{d X}{d t}=\frac{B}{A+2 X}+C \exp \left(-\frac{X}{L}\right)
$$

where $C$ and $L$ are the pre-exponential constant and the characteristic length, respectively. We have found that it is possible to fit the calculated values to the observed ones using eq. (2) much better than using eq. (1) in any cases, as shown by the dashed and solid lines, respectively, in Figs. 1-4. We discuss the temperature and oxygen partial pressure dependencies of the four parameters $B / A, B, C$, and $L$ below.

\subsection{Arrhenius Plots of the Fitting Parameter}

Figure 5 shows the Arrhenius plots of the linear rate constant $B / A$ for $C$ - and Si-faces. The values of $B / A$ for Si-face are one order of magnitude smaller than those for $C$ - face at any studied temperature, which is in agreement with the well-known experimental result indicating that the growth rate of Si-face is about 1/10 that of C-face. In the case of Si-face, the observed values of $B / A$ are on a straight line with an activation energy of $1.31 \mathrm{eV}$. While for $\mathrm{C}$-face, the values are on two straight lines, suggesting the existence of two activation energies, i.e., 0.75 and $1.76 \mathrm{eV}$, and the break point in the activation energy is around $1000^{\circ} \mathrm{C}(14)$. As we have measured the growth rates of $\mathrm{SiC} \mathrm{Si-face} \mathrm{in} \mathrm{the} \mathrm{oxide} \mathrm{thickness} \mathrm{range} \mathrm{less} \mathrm{than}$ $100 \mathrm{~nm}$, the diffusion limiting-step regime, in which the growth rate is inversely proportional to $X$, does not appear regardless of the temperatures used in this study. Therefore, the precision in determining the values of $B$, related to the diffusion coefficient, is not sufficient, and thus, we do not discuss the value of $B$ in this report. 


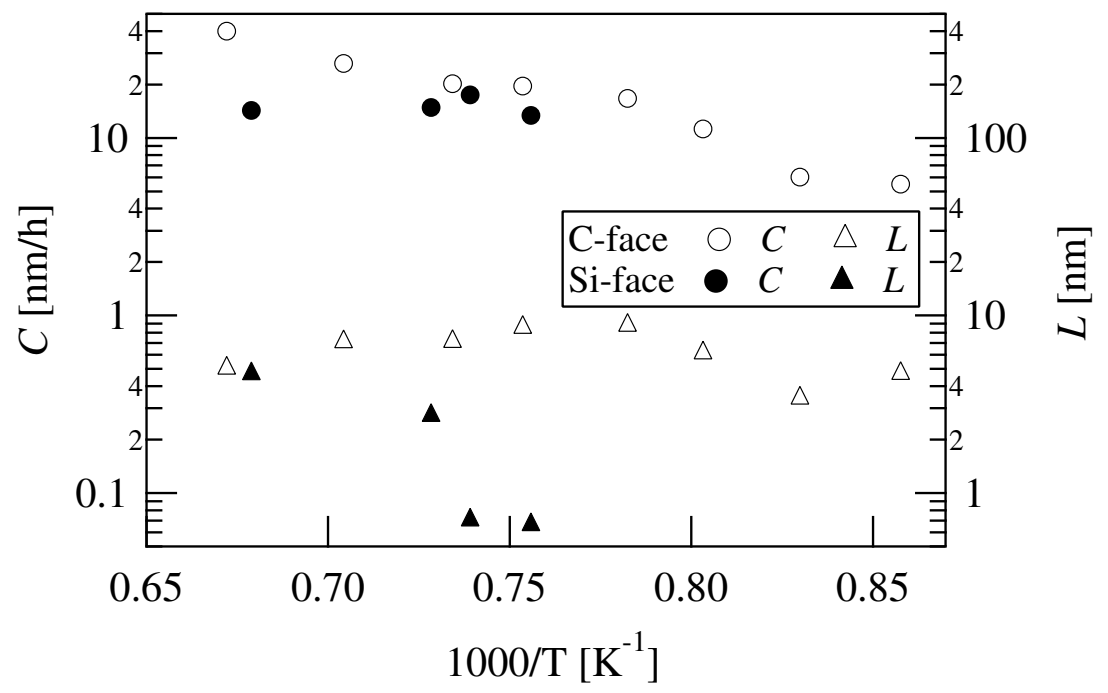

Fig. 6. Arrhenius plots of pre-exponential constant and characteristic length of the growth rate enhancement ( $\mathrm{C}$ and $\mathrm{L}$ ) for $\mathrm{C}$ - and Si-faces.

The values of $C /(B / A)$, which mean the magnitude of oxide growth enhancement, are around 2-6 for Si-face in the studied temperature range. On the other hand, those for C-face are less than 1 . These results suggest that the growth rate enhancement phenomenon is more marked for Si-face than for C-face. The temperature dependences of the values of $C$ and $L$ for $C$ - and Si-face shown in Fig. 6 . Figure 6 shows that the values of $C$ for $S i$-face are slightly smaller than those for $C$-face and almost independent of temperature, which is in contrast to the result for C-face. Figure 6 also shows that the values of $L$ for the Si-face, around $3 \mathrm{~nm}$ at $1100^{\circ} \mathrm{C}$, are smaller than those for $\mathrm{C}$-face, around $6 \mathrm{~nm}$ at the same temperature, and increase with temperature, which is also in contrast to the result for $\mathrm{C}$-face, i.e., almost independent of temperature. In the case of $\mathrm{Si}$ oxidation (8), the values of $L$ are around $7 \mathrm{~nm}$ and almost independent of temperature, and the values of $C$ increase with temperature. Therefore, it can be considered that the values of $L$ and the temperature dependences of $C$ and $L$ for $\mathrm{SiC} C$-face are almost the same as those for $\mathrm{Si}$, but different from those for $\mathrm{SiC} \mathrm{Si}$-face. As seen in the oxide thickness dependence of the growth rate, the surface reaction-limiting-step regime, in which the growth rate is constant against the oxide thickness $X$, does not appear in the temperature range studied for $\mathrm{SiC} \mathrm{C}$ face $(14 ; 16)$, as in the case for $\mathrm{Si}(8)$. This means that the oxidation mechanism of SiC C-face is in some sense similar to that of $\mathrm{Si}$, but that of $\mathrm{SiC} \mathrm{Si-face} \mathrm{is} \mathrm{very} \mathrm{different} \mathrm{from} \mathrm{that} \mathrm{of} \mathrm{Si}$. For $\mathrm{SiC} \mathrm{Si-face,} \mathrm{the} \mathrm{surface} \mathrm{reaction} \mathrm{rate} \mathrm{is} \mathrm{much} \mathrm{smaller} \mathrm{than} \mathrm{the} \mathrm{rate} \mathrm{limited} \mathrm{by} \mathrm{oxygen} \mathrm{diffusion,}$ compared with the cases of $\mathrm{SiC} \mathrm{C}$-face and $\mathrm{Si}$, which may cause the characteristics of the $\mathrm{SiC}$ $\mathrm{Si}$-face oxidation to differ from those for $\mathrm{SiC}$ C-face and $\mathrm{Si}$. 


\subsection{Oxygen Partial Pressure Dependencies of the Fitting Parameter}

We examined the oxygen partial pressure dependence of oxide growth rate at $X=0$, i.e., $C+B / A$, for $C$-face. As a result, the value of $C+B / A$ is propotional to oxygen partial pressure (17). When the oxide thickness $X$ is nearly equal to 0 , the oxide growth rate is essentially proportional to the quantity of oxidants that reach the interface between the oxide and $\mathrm{SiC}$ because this quantity is much lower than the number of $\mathrm{Si}$ atoms at the interface. Since the interfacial reaction rate when the oxide thickness $X$ approaches 0 is considered to depend not on partial pressure but on oxidation temperature, the initial growth rate $C+B / A$ is represented by the following expression:

$$
\mathrm{C}+\frac{B}{A} \propto k_{0} C_{\mathrm{O} 2}^{\mathrm{I}}
$$

where $k_{0}$ is the interfacial reaction rate when the oxide thickness $X$ approaches $0, C_{\mathrm{O} 2}$ is the concentration of oxidants, and the superscript ' $\mathrm{I}$ ' means the position at the $\mathrm{SiC}-\mathrm{SiO}_{2}$ interface. According to the Henry's law, the value of $\mathrm{C}_{\mathrm{O} 2}^{\mathrm{I}}$ is proportional to the oxygen partial pressure. Therefore, the initial growth rate $C+B / A$ should be proportional to the oxygen partial pressure, which is consistent with the experimental results obtained in this study.

While in the case of $B / A$, the oxygen partial pressure dependence showed a proportion to $\mathrm{p}^{0.5-0.6}(16 ; 17)$. This non-linear dependence is also seen in the case of Si oxidation though the exponent is slightly higher. As will be described below, the value of $B / A$ is considered as the quasi-state oxide growth rate and is determined by the balance between many factors, such as the quasi-steady concentration of $\mathrm{C}$ atoms at the interface, that of $\mathrm{Si}$ atoms emitted from the interface, interfacial reaction rate changing with oxide thickness. We believe that these are responsible for the non-linear dependence of $B / A$.

\subsection{Discussion}

Some Si oxidation models that describe the growth rate enhancement in the initial stage of oxidation have been proposed $(10-12 ; 18)$. The common view of these models is that the stress near/at the oxide-Si interface is closely related to the growth enhancement. Among these models, 'interfacial Si emission model' is known as showing the greatest ability to fit the experimental oxide growth rate curves. According to this model, $\mathrm{Si}$ atoms are emitted as interstitials into the oxide layers accompanied by oxidation of $\mathrm{Si}$, which is caused by the strain due to the expansion of Si lattices during oxidation. The oxidation rate at the interface is initially large and is suppressed by the accumulation of emitted Si atoms near the interface with increasing oxide thickness, i.e., the oxidation rate is not enhanced in the thin oxide regime but is quickly suppressed with increasing thickness. To describe this change in the interfacial reaction rate, Kageshima et al. introduce the following equation as the interfacial reaction rate constant, $k(10 ; 18)$ :

$$
k=k_{0}\left(1-\frac{C_{\mathrm{Si}}^{\mathrm{I}}}{C_{\mathrm{Si}}^{0}}\right)
$$

where $C_{\mathrm{Si}}^{\mathrm{I}}$ is the concentration of $\mathrm{Si}$ interstitials emitted at the interface and the $C_{\mathrm{Si}}^{0}$ is the solubility limit of $\mathrm{Si}$ interstitials in $\mathrm{SiO}_{2}$. It is noted that, in the Deal-Grove model (5), the function $k$ is assumed to be constant regardless of the oxidation thickness.

By the way, since the density of $\mathrm{Si}$ atoms in $\mathrm{SiC}\left(4.80 \times 10^{22} \mathrm{~cm}^{-3}\right)(19)$ is almost the same as that in $\mathrm{Si}\left(5 \times 10^{22} \mathrm{~cm}^{-3}\right)$ and the residual carbon is unlikely to exist at the oxide-SiC interface in the early stage of $\mathrm{SiC}$ oxidation, the stress near/at the interface is considered to be almost identical to the case of $\mathrm{Si}$ oxidation. Therefore, it is probable that atomic emission due to the interfacial stress also occurs for $\mathrm{SiC}$ oxidation and it also accounts for the growth enhancement 
in $\mathrm{SiC}$ oxidation. In addition, in the case of $\mathrm{SiC}$ oxidation, we should take $\mathrm{C}$ emission as well as $\mathrm{Si}$ emission into account because $\mathrm{SiC}$ consists of $\mathrm{Si}$ and $\mathrm{C}$ atoms.

Recently, we have proposed a SiC oxidation model , termed "Si and C emission model", taking the $\mathrm{Si}$ and $\mathrm{C}$ emissions into the oxide into account, which lead to a reduction of interfacial reaction rate (20). Considering $\mathrm{Si}$ and $\mathrm{C}$ atoms emitted from the interface during the oxidation as well as the oxidation process of $\mathrm{C}$, the reaction equation for $\mathrm{SiC}$ oxidation can be written as,

$$
\begin{gathered}
\mathrm{SiC}+\left(2-v_{\mathrm{Si}}-v_{\mathrm{C}}-\frac{\alpha}{2}\right) \mathrm{O}_{2} \rightarrow\left(1-v_{\mathrm{Si}}\right) \mathrm{SiO}_{2}+v_{\mathrm{Si}} \mathrm{Si} \\
+v_{\mathrm{C}} \mathrm{C}+\alpha \mathrm{CO}+\left(1-v_{\mathrm{C}}-\alpha\right) \mathrm{CO}_{2}
\end{gathered}
$$

where $v$ and $\alpha$ denote the interfacial emission rate and the production rate of $\mathrm{CO}$, respectively. In the case of $\mathrm{Si}$ oxidation, the growth rate in thick oxide regime is determined by the parabolic rate constant $B$ as is obvious if we consider the condition $A \ll 2 X$ for eqs. $(1,2)$. Song et al. proposed a modified Deal-Grove model that takes the out-diffusion of $\mathrm{CO}$ into account by modifying the parabolic rate constant $B$ by a factor of 1.5 (called 'normalizing factor' (21)), and through this model, explained the oxidation process of $\mathrm{SiC}$ in the parabolic oxidation rate regime (6). For the $\mathrm{Si}$ and $\mathrm{C}$ emission model, the normalizing factor corresponds to the coefficient of the oxidant shown in eq. (5), i.e. $\left(2-v_{\mathrm{Si}}-v_{\mathrm{C}}-\alpha / 2\right)$. Since Song's model assumed that there is no interfacial atomic emission (i.e. $v_{\mathrm{Si}}=v_{\mathrm{C}}=0$ ) and carbonaceous products consist of only $\mathrm{CO}$ (i.e. $\alpha=1$ ), for this case, it is obvious that the coefficient of the oxidant in eq. (5) equals 1.5. Actually, it has been found in our study that this coefficient is 1.53 by fitting the calculated growth rates to the measured ones (20). Therefore, for C-face, the parameters $v_{\mathrm{Si}}, v_{\mathrm{C}}$, and $\alpha$ should be close to those assumed in the Song's model. While for $\mathrm{Si}$-face, this coefficient results in a lower value. According to our recent work $(20 ; 22)$, the most significant differences between C- and Si-face oxidation are those in $k_{0}$ and $v_{\mathrm{Si}}$. Therefore, it can be consider that the difference in $v_{\mathrm{Si}}$ leads to that in the coefficient of oxidant. Anyway, it is believed that the different $\mathrm{B}$ from that of $\mathrm{Si}$ oxidation is necessary to reproduce the growth rate in the diffusion rate-limiting region $(4 ; 6 ; 21 ; 23)$ because $\mathrm{CO}$ and $\mathrm{CO}_{2}$ production is neglected. In the case of $\mathrm{Si}$ oxidation, the interfacial reaction rate (i.e. eq. (4)) is introduced by assuming that the value of $C_{\mathrm{Si}}^{\mathrm{I}}$ does not exceed the $C_{\mathrm{Si}}^{0}$ though the reaction rate decreases with increase of $C_{\mathrm{Si}}^{\mathrm{I}}$. Based on this idea, the interfacial reaction rate for $\mathrm{SiC}$ is thought to be given by multiplying decreasing functions for Si and C (20):

$$
k=k_{0}\left(1-\frac{C_{\mathrm{Si}}^{\mathrm{I}}}{C_{\mathrm{Si}}^{0}}\right)\left(1-\frac{C_{\mathrm{C}}^{\mathrm{I}}}{C_{\mathrm{C}}^{0}}\right) .
$$




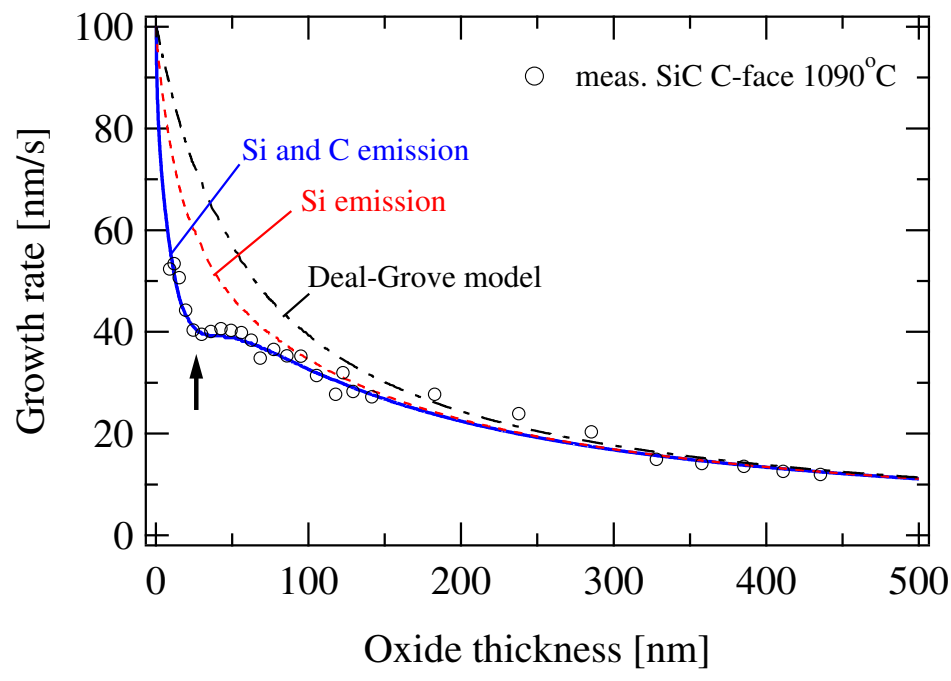

Fig. 7. Oxide thickness dependence of growth rates for C-faces.

This equation implies that the growth rate in the initial stage of oxidation should reduce by two steps because the accumulation rates for $\mathrm{Si}$ and $\mathrm{C}$ interstitials should be different from each other, and hence, the oxidation time when the concentration of interstitial saturates should be different between $\mathrm{Si}$ and $\mathrm{C}$ interstitial. This prediction will be evidenced in the next paragraph.

Figure 7 shows the oxide growth rates observed for C - face at $1090^{\circ} \mathrm{C}$ (circles). Also shown in the figure are the growth rates given by the $\mathrm{Si}$ and $\mathrm{C}$ emission model (solid lines), the $\mathrm{Si}$ emission model, and the model that does not take account of both $\mathrm{Si}$ and $\mathrm{C}$ emission, i.e., the Deal-Grove model (broken line and double broken line, respectively). We note that the same parameters were used for these three $\mathrm{SiC}$ oxidation models. Figure 7 shows that the $\mathrm{Si}$ and $\mathrm{C}$ emission model reproduces the experimental values better than the other two models. In particular, the dip in the thickness dependence of the growth rate seen around $20 \mathrm{~nm}$ (pointed by the arrow in the figure), which cannot be reproduced by the Si emission model or the DealGrove model no matter how well the calculation are tuned, can be well reproduced by the $\mathrm{Si}$ and $C$ emission model. These results suggest that the $C$ interstitials play an important role in the reduction of the oxidation rate, similarly to the role of the Si interstitials. Moreover, from the fact that the drop in growth rate in the initial stage of oxidation is larger for the Si and C emission model than in the case of taking only Si emission into account, we found that the accumulation of $\mathrm{C}$ interstitials is faster than that of $\mathrm{Si}$ interstitials and that the accumulation of $\mathrm{C}$ interstitials is more effective in the thin oxide regime.

\section{Conclusion}

By performing in-situ spectroscopic ellipsometry, we have, for the first time, observed the growth enhancement in oxide growth rate at the initial stage of $\mathrm{SiC}$ oxidation, which means that the $\mathrm{D}-\mathrm{G}$ model is not suitable for $\mathrm{SiC}$ oxidation in the whole thickness regime, as in the 
case of Si oxidation. We have also observed the occurrence of the oxide growth rate enhancement at any oxidation temperature and oxygen partial pressure measured both in the cases of $\mathrm{C}$ - and Si-faces. We found that the growth rate of $\mathrm{SiC}$ for both polar faces can be well represented by the empirical equation proposed by Massoud et al. using the four adjusting parameters $B / A, B, C$, and $L$, and that the values of $B / A, C$, and $L$, and the temperature dependences of $C$ and $L$ for $S i$-face are different from those for $C$-face. Finally, we have discussed the mechanism of the growth rate enhancement in the initial stage of oxidation by comparing with the oxidation mechanism of Si.

\section{References}

[1] H. Matsunami: Jpn. J. Appl. Phys. Part 143 (2004) 6835.

[2] S. Yoshida: Electric Refractory Materials, ed. Y. Kumashiro (Dekker, New York, 2000) 437.

[3] V. V. Afanas'ev and A. Stesmans: Appl. Phys. Lett. 71 (1997) 3844.

[4] K. Kakubari, R. Kuboki, Y. Hijikata, H. Yaguchi, and S. Yoshida: Mater. Sci. Forum 527529 (2006) 1031.

[5] B. E. Deal and A. S. Grove: J. Appl. Phys. 36 (1965) 3770.

[6] Y. Song, S. Dhar, L. C. Feldman, G. Chung and J. R. Williams: J. Appl. Phys. 95 (2004) 4953.

[7] A. S. Grove: Physics and Technology of Semiconductor Devices (John Wiley \& Sons, New York, 1967) 31.

[8] H. Z. Massoud, J. D. Plummer, and E. A. Irene: J. Electrochem. Soc. 132 (1985) 2685.

[9] H. Z. Massoud, J. D. Plummer, and E. A. Irene: J. Electrochem. Soc. 132 (1985) 2693.

[10] H. Kageshima, K. Shiraishi, and M. Uematsu: Jpn. J. Appl. Phys. Part 238 (1999) L971.

[11] S. Ogawa and Y. Takakuwa: Jpn. J. Appl. Phys. 45 (2006) 7063.

[12] T. Watanabe, K. Tatsumura, and I. Ohdomari: Phys. Rev. Lett. 96 (2006) 196102.

[13] T. Iida, Y. Tomioka, M. Midorikawa, H. Tsukada, M. Orihara, Y. Hijikata, H. Yaguchi, M. Yoshikawa, H. Itoh, Y. Ishida, and S. Yoshida: Jpn. J. Appl. Phys. Part 141 (2002) 800.

[14] T. Yamamoto, Y. Hijikata, H. Yaguchi, and S. Yoshida: Jpn. J. Appl. Phys 46 (2007) L770.

[15] T. Yamamoto, Y. Hijikata, H. Yaguchi, and S. Yoshida: Jpn. J. Appl. Phys. 47 (2008) 7803.

[16] T. Yamamoto, Y. Hijikata, H. Yaguchi, and S. Yoshida: Mater. Sci. Forum. 600-603 (2009) 667.

[17] K. Kouda, Y. Hijikata, H. Yaguchi, and S. Yoshida: Mater. Sci. Forum. 645-648 (2010) 813.

[18] M. Uematsu, H. Kageshima, and K. Shiraishi: J. Appl. Phys. 89 (2001) 1948.

[19] Y. Hijikata, H. Yaguchi, S. Yoshida, Y. Takata, K. Kobayashi, H. Nohira, and T. Hattori: J. Appl. Phys. 100 (2006) 053710.

[20] Y. Hijikata, H. Yaguchi, and S. Yoshida: Appl. Phys. Express 2 (2009) 021203.

[21] E. A. Ray, J. Rozen, S. Dhar, L. C. Feldman, and J. R. Williams: J. Appl. Phys. 103 (2008) 023522.

[22] Y. Hijikata, H. Yaguchi, and S. Yoshida: Mater. Sci. Forum 615-617 (2009) 489.

[23] Y. Hijikata, T. Yamamoto, H. Yaguchi, and S. Yoshida: Mater. Sci. Forum 600-603 (2009) 663. 
www.intechopen.com 


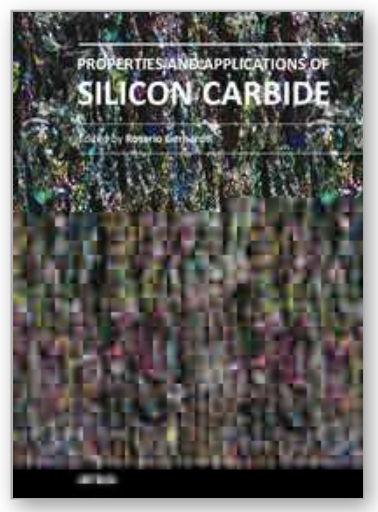

\author{
Properties and Applications of Silicon Carbide \\ Edited by Prof. Rosario Gerhardt
}

ISBN 978-953-307-201-2

Hard cover, 536 pages

Publisher InTech

Published online 04, April, 2011

Published in print edition April, 2011

In this book, we explore an eclectic mix of articles that highlight some new potential applications of $\mathrm{SiC}$ and different ways to achieve specific properties. Some articles describe well-established processing methods, while others highlight phase equilibria or machining methods. A resurgence of interest in the structural arena is evident, while new ways to utilize the interesting electromagnetic properties of SiC continue to increase.

\title{
How to reference
}

In order to correctly reference this scholarly work, feel free to copy and paste the following:

Yasuto Hijikata, Hiroyuki Yaguchi and Sadafumi Yoshida (2011). Growth Rate Enhancement of Silicon-Carbide Oxidation in Thin Oxide Regime, Properties and Applications of Silicon Carbide, Prof. Rosario Gerhardt (Ed.), ISBN: 978-953-307-201-2, InTech, Available from: http://www.intechopen.com/books/properties-andapplications-of-silicon-carbide/growth-rate-enhancement-of-silicon-carbide-oxidation-in-thin-oxide-regime

\section{INTECH}

open science | open minds

\author{
InTech Europe \\ University Campus STeP Ri \\ Slavka Krautzeka 83/A \\ 51000 Rijeka, Croatia \\ Phone: +385 (51) 770447 \\ Fax: +385 (51) 686166 \\ www.intechopen.com
}

\author{
InTech China \\ Unit 405, Office Block, Hotel Equatorial Shanghai \\ No.65, Yan An Road (West), Shanghai, 200040, China \\ 中国上海市延安西路65号上海国际贵都大饭店办公楼 405 单元 \\ Phone: +86-21-62489820 \\ Fax: +86-21-62489821
}


(C) 2011 The Author(s). Licensee IntechOpen. This chapter is distributed under the terms of the Creative Commons Attribution-NonCommercialShareAlike-3.0 License, which permits use, distribution and reproduction for non-commercial purposes, provided the original is properly cited and derivative works building on this content are distributed under the same license. 